\title{
Transportation Optimization of Ribbon Floating Bridges: Analytical and Experimental Investigation
}

\author{
Giannin Viecili ${ }^{1}$, Abd El Halim Omar Abd El Halim ${ }^{1, *}$, Abass Braimah ${ }^{1}$ and Osama El-Desouky ${ }^{2}$ \\ ${ }^{I}$ Civil and Environmental Engineering Department Carleton University, 1125 Colonel By Drive, Ottawa, ON, Canada, \\ KIS $5 B 6$ \\ ${ }^{2}$ Civil Engineering Department, Military Technical College, Cairo, Egypt
}

\begin{abstract}
Floating bridges are an economical and practical alternative for crossing water obstacles, especially in times of emergencies and conflicts. Ribbon pontoon floating bridges are a special type of floating bridge designed, built, stockpiled and deployed by the military and emergency management organizations in times of need. They are light-weight, fast to erect, and use the buoyancy of water to aid in supporting their self-weight and traffic loads imposed on the bridge.

With increasing vehicular weights and fast bridge traversing time requirements, it has become necessary to develop reliable analytical tools capable of designing and analyzing floating bridges. It is critical to ensure that ribbon pontoon floating bridges can accommodate heavier vehicles, and at the same time reduce the spacing between successive vehicles to achieve greater transportation and economic efficiency.

This paper presents the outline and results of an analytical and experimental research program designed to study the dynamic behavior of ribbon pontoon floating bridges under two-axle vehicular loading. An innovative experimental model was designed, constructed, and used in the experimental study. The developed analytical model predicted, with reasonable accuracy, maximum bridge displacements at different vehicle speeds and weights when compared with the experimental results.
\end{abstract}

Keywords: Floating bridge, pontoon, numerical analysis, experimental investigation of pontoon bridge, buoyancy, MLC.

\section{INTRODUCTION}

Bridges have significantly evolved over the years, providing people with the opportunity to have better and safer access to trade and communication. They provide a means of crossing barriers in nature such as lakes, canyons, and rivers. Bridges are used, and sometimes essential, to cross manmade obstacles as well; for example highways, roads and trenches. They are one of the most important transportation infrastructures as they are created out of necessity and can be used to accommodate cars, trains, and pedestrians. Bridges are common in almost all transportation modes.

Bridges provide linkages between communities, cities or two countries; thus they are essential for the economic development and cultural exchange among peoples and nations. The alleviation of traffic congestion is also an application of bridges contributing to the welfare of the public. Bridges are not only used for commercial purposes, they also play a strategic and important role during times of war. In order for an army to cross an unexpected or

*Address correspondence to this author at the Civil and Environmental Engineering Department, Carleton University, 1125 Colonel By Drive, Ottawa, ON, Canada, K1S 5B6; Tel.: (613) 520-2600; Ext: 3393;

Fax: (613) 520-3951; E-mail: ahalim@ccs.carleton.ca obstructive body of water, where it's too deep to travel through and time is of the essence, ribbon pontoon floating bridges are vital for crossing. They are used to connect the gaps between shores and between ships and the shoreline. They are a fast and essential solution to provide a safe route for the evacuation of people and transportation of troops, equipment, and supplies in times of emergency.

Bridges are typically designed to be fixed or permanent infrastructures with a long lifespan. However, there are cases when permanent bridges are uneconomical and temporary structures are required; e.g. during state of emergencies or wars when permanent bridges could be damaged or are nonexistent where they are needed. The origins of the use of pontoon bridges for temporary military purposes can be traced back to about 2000 BC [1]. Supposedly, King Xerxes of Persia led his army to fight the Greeks using a pontoon bridge between the Dardanelles, Turkey and Thermopylae, Greece in 480 BC. This bridge consisted of over 300 boats tied together, with a deck composed of wooden planks [2]. Today, most floating bridges are made from light-weight concrete, steel, aluminum alloys and composite materials [3, 4]. They are constructed on bodies of water where they use buoyancy to support their self-weight and traffic loading. They are usually temporary structures with a relatively shorter construction time in comparison with fixed bridges. 
Floating bridges have several advantages over conventional fixed bridges. Their design to use buoyancy force to resist vehicular loading leads to lighter structures than conventional bridges. They offer economic and practical solution for crossing obstacles where conditions are unsuitable for conventional structures. Examples of locations not suitable for conventional fixed bridges include [5]:

- $\quad$ areas prone to severe earthquakes

- locations of deep waters where it is uneconomical to found piers of conventional bridges

- $\quad$ areas of poor to unstable soil conditions or inadequate capacity to resist bridge loads

- areas where construction of fixed bridges can destroy and disturb marine life and habitats.

Additionally, there are situations when a practical staging area is not available, or it is too difficult, to construct fixed or permanent bridges. To address these shortcomings, temporary bridges are needed. Ribbon pontoon floating bridges have the ability to be transported to the site and assembled for use. Once they are no longer required they are disassembled and moved to another area where they are required. Floating bridges are predominantly used by the military because they can be transported with troops and erected rapidly when needed. According to Watanabe and Utsunomiya [5] the cost of construction of a floating bridge can be three to five times less than that of a conventional fixed bridge.
Floating bridges can be classified in terms of their structural system as: separated pontoon, continuous pontoon, or ribbon floating bridges [3-5]. Separated pontoon floating bridges are supported by discrete pontoon foundations (Fig. 1b) while continuous pontoon (pontoon girder) floating bridges have full surface contact with the water (Fig. 1a). There are also floating bridges with semi-submerged foundations (Fig. 1c) or with gravity foundations (Fig. 1d). Lastly, in (Fig. 1e), a long span separated foundation bridge is presented. Ribbon (rapid deployment) floating bridges are a type of continuous pontoon floating bridge consisting of modular pontoons assembled together in the field [1].

Separated pontoon floating bridges and continuous pontoon floating bridges are the most commonly used types of floating bridges for civilian water crossing [6,7]. These types of floating bridges have been constructed as permanent fixed bridges, for example the Bergsoysund pontoon bridge in Norway and the Lacey V. Murrow Bridge in Seattle, USA. The bridges investigated in this report, Ribbon floating bridges, are primarily used by military forces and emergency management organisations as they are rapidly deployed and connected to form a road surface for vehicular traffic in time of war, natural disasters, and emergencies. For example, it takes only about $30-50$ minutes to assemble a $382 \mathrm{~m}$ bridge in comparison to months or years to build a permanent bridge structure [8]. Ribbon pontoon floating bridges are usually transported by semi-trailers, launched and deployed into the water and tugged into place by boats [9]. Thus ribbon floating bridges are important assets for the military and emergency management organizations.

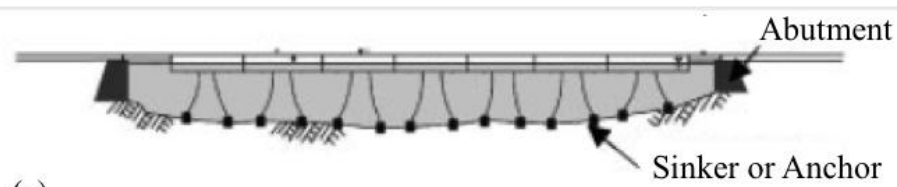

(a)
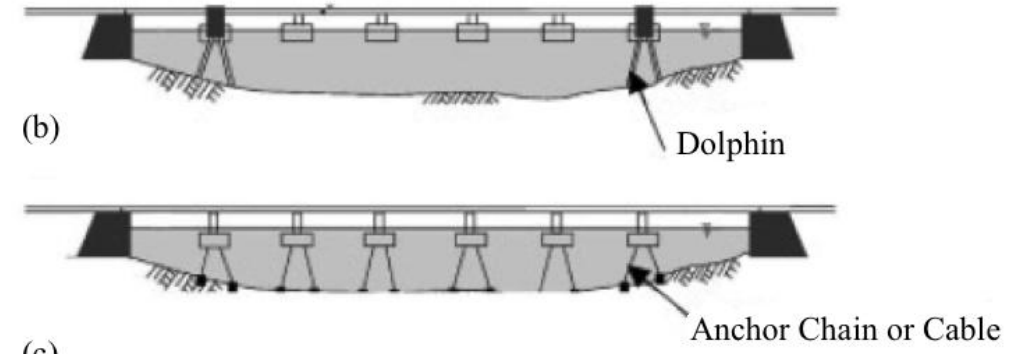

(c)

Anchor Chain or Cable

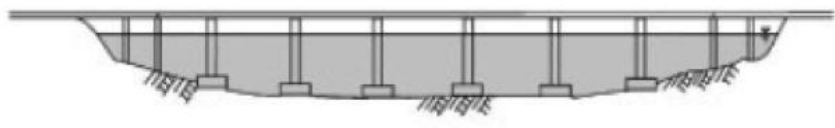

(d)

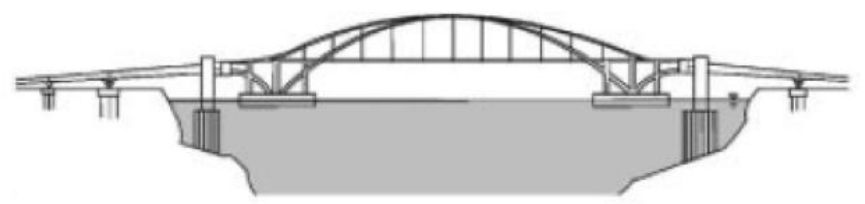

(e)

Fig. (1). Floating bridges (a) continuous pontoon bridge (b) separated pontoon bridge (c) semi-submerged foundation bridge (d) gravity foundation bridge (e) long span separated bridge [1]. 
Ribbon floating bridges consist of a number of modular pontoons connected together to provide a roadway over water obstacle for vehicles and other military equipment as shown in Fig. (2). The unit pontoon can be easily and rapidly assembled and disassembled under emergency conditions. Each unit is made of a closed-shape section with floating abilities. Most commonly, the pontoon unit includes two roadways and two bows.

According to Hornbeck et al. [23], the essential vehicle design crossing speed for vehicles up to Military Load Class 30 (MLC 30) is $25 \mathrm{~km} / \mathrm{h}$ while the essential vehicle design crossing speed for vehicles above MLC 30 is $15 \mathrm{~km} / \mathrm{h}$. Additionally, the minimum distance between successive vehicle axles is specified as $30.5 \mathrm{~m}$ [10]. Under exceptional conditions a "Caution Crossing" state can be invoked where heavier than design vehicles are allowed to cross ribbon floating bridges under strict prescribed conditions that ensure the same level of safety as under normal crossing conditions [23]. During "Caution Crossing", vehicle speed is limited to below $5 \mathrm{~km} / \mathrm{h}$ and breaking, accelerating, and gear changing are prohibited [10]. The distance between successive vehicles must be greater than the $30.5 \mathrm{~m}$ specified for normal crossing [10].

Vehicles traversing a floating bridge generate dynamic waves that can lead to large amplification of the deflections and stresses of the bridge. According to the guidelines provided in the Military Load Classification (MLC) most floating bridges are designed to withstand stresses and strains generated by MLC 60 vehicles. With pressing needs for heavier equipment crossing and shorter crossing times, new bridges are expected to be designed to allow the heavier recent MLC 70 vehicles. In addition, it is important to examine the capacities of existing ribbon pontoon floating bridges for the MLC 70 vehicle crossing. This will allay any fears of failure or serious damage to the pontoons.
Therefore, one of the main objectives of military and emergency planners is to optimize the transportability of existing pontoon bridges. The evaluation of bridges can be accomplished through field testing or numerical modelling. Field testing can be cost prohibitive and time consuming and might not be capable of evaluating all the important parameters required for understanding the behaviour of pontoon floating bridges and establishing the level of safety available for heavy vehicle crossing. Numerical modelling techniques on the other hand is capable of investigating several factors including maximum traversing speed, minimum distance between two successive vehicles and maximum allowable combination of speed and vehicle weight crossing the bridge. Numerical models or analytical evaluation of floating bridges, knowledge of which is currently limited, must first be validated against experimental results to gain some confidence in the results.

\section{OBJECTIVES}

The popularity of using floating bridges for vehicular crossing of water bodies is increasing. This is due to the advantages afforded by buoyancy forces in supporting the vehicular loading. There are interests around the world in the design and construction of floating cities and terminals [5]. Unlike conventional bridges, however, there is a lack of research and understanding of the behaviour of floating bridges under dynamic vehicular loading. Also, no unified methodology exists for the analysis of the dynamic behavior of floating bridges. It is therefore essential to study the behaviour of floating bridges under dynamic vehicular loading and to develop an analytical procedure for their preliminary design.

This paper presents an on-going research program to investigate the behaviour of ribbon pontoon floating bridges under vehicle loading. The research program consist of

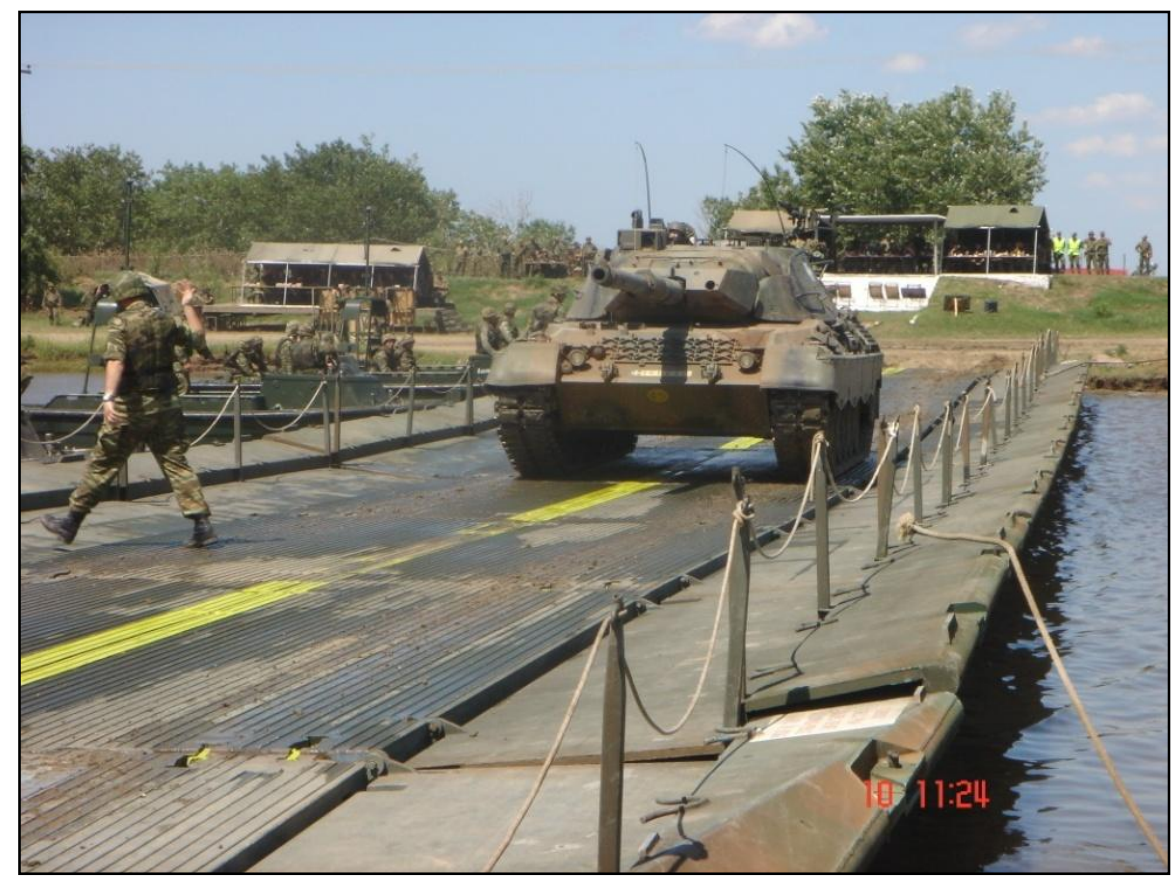

Fig. (2). Ribbon floating bridge [11]. 
experimental and analytical phases. In the experimental phase a model hinged ribbon floating bridge was constructed in the laboratory and tested under two-axle vehicle loading at different speeds and vehicle weights. The analytical phase of the research program included development of an analytical model for investigating the behaviour of ribbon pontoon floating bridges. The analytical model was validated with the experimental results and used in a parametric study to establish the effects of different parameters on the behaviour of ribbon pontoon floating bridges.

The objectives of the research program were to provide much needed experimental data on behaviour of ribbon floating bridges, establish the effect of vehicle mass and speed on the behaviour of ribbon pontoon floating bridges, and the effect of successive axle distance on the behaviour of ribbon floating bridges.

The results from the research program will be used to optimize the vehicle weights, vehicle crossing speed, and axle spacing to achieve greater economic efficiency.

\section{ANALYTICAL MODELLING OF FLOATING BRID- GES}

In the analytical and numerical investigations, the floating ribbon bridge was treated as a beam resting on an elastic foundation. The foundation was further assumed to have elastic stiffness that simulated the hydrostatic effects of water [12-15]. Thambiratnam and Zhuge [16] presented a comprehensive study where the effect of various variables on the dynamic behaviour of floating bridges were considered. In their investigation Thambiratnam and Zhuge included the effect of length of the bridge, speed of a moving point load, and the stiffness of the foundation and concluded that dynamic amplification factors for deflections and stresses increased with increasing point load speeds.

Thambiratnam and Zhuge's conclusion did not indicated whether the amplification of deflections and stresses will persist at all vehicle speeds. The increase of deflection and stress amplification places a limit on the level of optimization of floating bridge crossing that can be achieved through increase of vehicle speed. Therefore, the experimental investigation, based on utilizing a laboratory scale model ribbon pontoon bridge, vehicle weights and speeds, was designed to investigate the rate of deflection and stress amplification with increased speed. The experimental investigation was also required to validate the result of a numerical model developed at Carleton University [12].

The effect of water depth on floating bridges carrying vehicular loads was investigated by Zhang et al. [17]. The authors developed an analytical model for both separated and continuous pontoon floating bridges to investigate their dynamic responses due to moving loads, for diverse water depths. In this study, the hydrodynamic influence coefficients used to study different water depths, as well as the dynamic responses of the bridges, were estimated by the use of the Galerkin Method of Weighted Residuals and the Boundary Element Method [17]. Additionally, the Potential Theory aided in the consideration of hydrodynamic effects (such as added mass and radiation damping). The bridge was modeled as simply-supported, resting on equally spaced elastic springs, representing the stiffness of the supporting water. The authors assumed that the bridge had uniform material properties, that the load was traveling at a constant speed, and that the water depth was infinite [17]. The authors concluded that water depth had a negligible effect while the applied vehicular load had a significant effect on the dynamic response of the floating bridge [7].

Many researchers have indicated that the choice of vehicle model used in numerical analysis is essential for determining the dynamic characteristics, and therefore the response of the bridge. Humar and Kashif [18] and Qui [19] used spring-mass-damper system to model the vehicle in their research and reported accurate results without the accompanying complexity or loss of numerical efficiency. The spring-mass-damper system consists of a sprung mass and an unsprung mass connected by a spring, a damper and traveling at a constant speed. Humar and Kashif [18] further simplified the moving sprung mass model by assuming negligible bridge damping. The authors ignored unsprung mass and damping of the vehicle.

Humar and Kashif [18] studied the dynamic response of a simply supported bridge traversed by moving vehicles. They determined the significant parameters in investigating dynamic response, by using the simplified vehicle model. The parameters investigated were vehicle speed, ratio of the mass of vehicle to the mass of the bridge, and ratio of the vehicle frequency to the bridge frequency. In their study, the vehicles were modeled both as single-axle and two-axle spring mass systems with the bridge represented by a beam element. Humar and Kashif used sprung and unsprung masses, connected through springs and viscous dashpots and the bridge element. The single-axle spring mass model proved to provide accurate results when the axle spacing was minimal compared to the bridge span. When the axle spacing to bridge span ratio is larger, the two-axle spring mass model provided better results, and a smaller deflection. The literature review did not reveal any research work on floating bridges using spring-mass-damper system for single- and/or two-axle vehicle model.

This paper presents an analytical model using springmass-damper system on ribbon pontoon floating bridges. Each pontoon of the ribbon floating bridge was modeled as a space frame element with six degrees of freedom at each node; three translational $(x-, y-, z$-axis) and three rotational $(x-, y-, z$-axis) degrees of freedom. Each space frame element had a uniform cross-sectional area, moment of inertia about the $x$ and $y$-axis, polar moment of inertia about the $\mathrm{z}$ axis, modulus of elasticity, and shear modulus. The ribbon floating bridge, consisting of a number of modular pontoons with a hinged connection, was assumed to have a span $L$, uniform mass per unit length, and flexural rigidity EI. The bridge was modeled as simply supported on the two shores (banks). The reaction along the wetted surface area of the bridge length was modeled by elastic springs with stiffness per unit length $k_{w}$.

In accordance with Archimedes Principle of Floatation, which states that the buoyancy force exerted on a floating body is equal to the weight of the fluid displaced by the body, the floating bridge experiences a buoyancy force equal to the mass of water it displaces. The buoyancy force can be 
represented by elastic springs acting on the bridge $[4,13,14$, 15]. The bridge behaves as a beam on elastic foundation with foundation elastic modulus equal to the buoyancy stiffness (Fig. 3). For the heave motion, the buoyancy stiffness is given as $k_{w}=\rho_{w} g B$ while for the roll motion the buoyancy stiffness is given as $k_{w}=\rho_{w} g B^{3} / 12$, where $\rho_{w}$ is the density of water, $g$ is the gravitational acceleration, and $B$ the width of the rectangular bridge section. Fig. (4) presents the buoyancy force as a function of the submerged depth of the floating bridge. Seif and Koulaei [4] proposed the buoyancy force be modeled as linearly proportional to the floating bridge (pontoon) displacement into water.

Apart from the vehicle loading, self-weight, and the buoyancy force, floating bridges are also subjected to transverse loading from the water current, wave loading, wind loading, and maybe to earthquake loading. Only the vehicle load, self-weight and buoyancy force are considered in this paper.

The finite element model for each pontoon was discretized with each element having only four degrees of freedom. The nodal displacements within each of these elements were found by the superposition of a number of shape functions. Each shape function was multiplied by a generalized coordinate (the deflections, axial displacements and rotations). The shape functions for bending behavior in the $x-y$ (vertical) and $x-z$ (horizontal) planes are given as follows, where $L$ is the element length [20,22]:

$$
\begin{aligned}
& \psi_{1}=1-3 \frac{x^{2}}{L^{2}}+2 \frac{x^{3}}{L^{3}} \\
& \psi_{2}=x-2 \frac{x^{2}}{L}+\frac{x^{3}}{L^{2}} \\
& \psi_{3}=3 \frac{x^{2}}{L^{2}}-2 \frac{x^{3}}{L^{3}} \\
& \psi_{4}=-\frac{x^{2}}{L}+\frac{x^{3}}{L^{2}}
\end{aligned}
$$

While the shape functions for the torsional and axial behavior are given as:

$\psi_{t_{1}}=1-\frac{x}{L}$

$\psi_{t_{2}}=\frac{x}{L}$

The deflected shape of the bridge is expressed as a superposition of the product of the shape functions and the corresponding degrees of freedom in accordance with equation 7 .

$u(x, t)=\Delta_{1 y}(t) \psi_{1}(x)+\theta_{1 z}(t) \psi_{2}(x)+\Delta_{2 y}(t) \psi_{3}(x)+$ $\theta_{2 z} \psi_{4}(x)$

where $\Delta_{1 y}$ and $\Delta_{2 y}$ are the nodal vertical displacements along $y$-axis, and $\theta_{1 z}$ and $\theta_{2 z}$ are the nodal rotation about $z$ axis at the two nodes of the space frame element.

Since the vehicle is represented with a dynamic model with spring and damping characteristics, its equation of motion relative to the floating bridge is expressed as the motion of its point of contact with the bridge, $\eta$.

$$
\begin{aligned}
& \eta=\Delta_{1 y}(t) \psi_{1}(x)+\theta_{1 z}(t) \psi_{2}(x)+\Delta_{2 y}(t) \psi_{3}(x)+ \\
& \theta_{2 z}(t) \psi_{4}(x)
\end{aligned}
$$

where $x=v t$ is the $x$-coordinate along the bridge length when the vehicle is traveling at constant speed, $v$. The first and second derivatives of the equation of motion at the point of contact of the vehicle load (Equation 8) gives velocity and acceleration. With a known contact point of behavior, the response of the vehicle with respect to the contact point equation of motion can be determined using the stiffness and damping characteristics of the vehicle; as expressed by Humar and Kashif [18].

The equation of motion of the floating bridge can be represented in matrix formulation by Equation 9 .

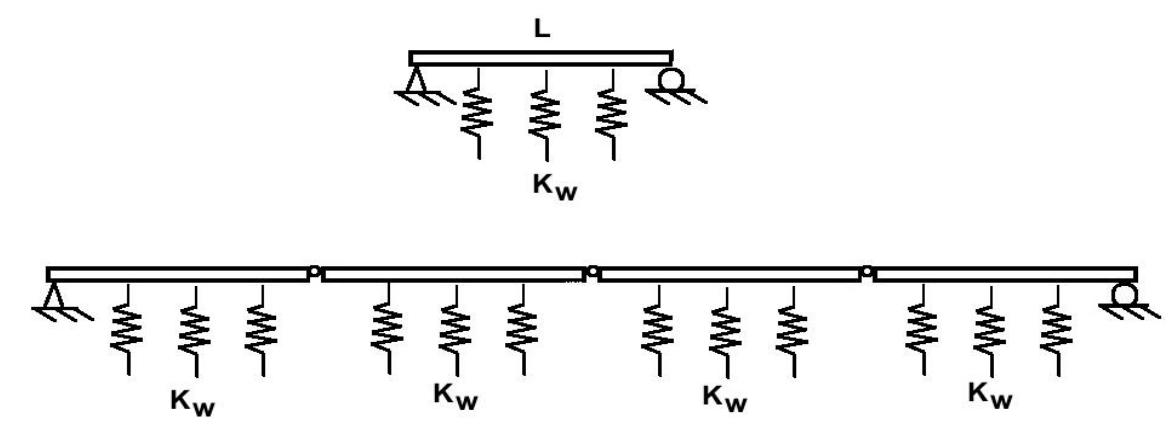

Fig. (3). Structural model for hinged ribbon floating bridge.

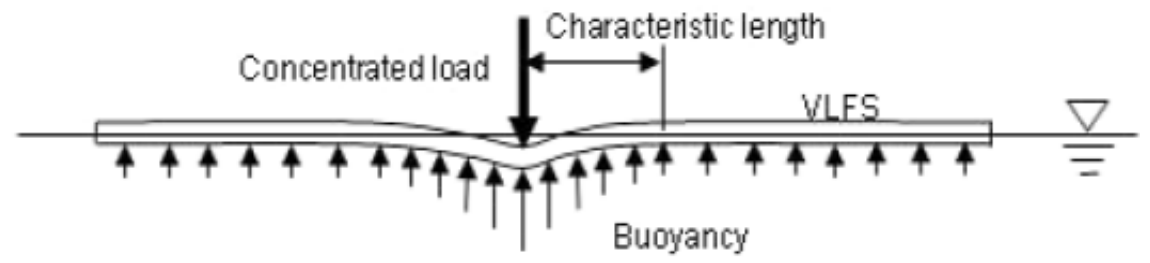

Fig. (4). Buoyancy forces acting on a VLFS [21]. 
$\left[M_{G}\right]\{\ddot{D}\}+\left[C_{G}\right]\{\dot{D}\}+\left[K_{G}\right]\{D\}=\{P\}$

Where

$\{D\}$ is the global displacement vector of the bridge.

$\{\dot{D}\}$ is the first time derivative of the global displacement vector (velocity) of the bridge.

$\{\ddot{D}\}$ is the second time derivative of the global displacement vector (acceleration) of the bridge.

$\left[M_{G}\right]$ is the global mass matrix of the bridge.

$\left[C_{G}\right]$ is the global damping matrix of the bridge.

$\left[K_{G}\right]$ is the global stiffness matrix of the bridge.

$\{P\}$ is the global load vector acting on the bridge.

The global mass matrix is expressed for each element with the distributed mass per unit length of the bridge. In addition, an added mass is taken into consideration in the global mass matrix to account for the volume of surrounding water the bridge displaces due to deflections; the bridge displaces variations of volumes of water as it accelerates and/or decelerates. Additionally, the global stiffness is the sum of the pontoon element stiffness matrix and the stiffness due to the underlying water which was represented by elastic springs. The global damping matrix is derived from Rayleigh or Proportional damping (Equation 10), where the damping is expressed as a linear combination of the stiffness matrix and the mass matrix of the bridge. The global load vector matrix is the resultant of the free body diagram of the loads acting on the bridge (Fig. 5) and considers torsional moments due to eccentricity as well as concentrated loads.

$\left[C_{G}\right]=\alpha\left[K_{G}\right]+\beta\left[M_{G}\right]$

Where $\alpha$ and $\beta$ are the stiffness and mass proportional damping constants computed using the first and second bending modes of the bridge.

Equation 9 is solved by using Newmark's average acceleration time matching technique in which the equation of motion is solved at each time step for the associated displacement. This allows for the determination of moment and shear forces on each pontoon element as a function of time.

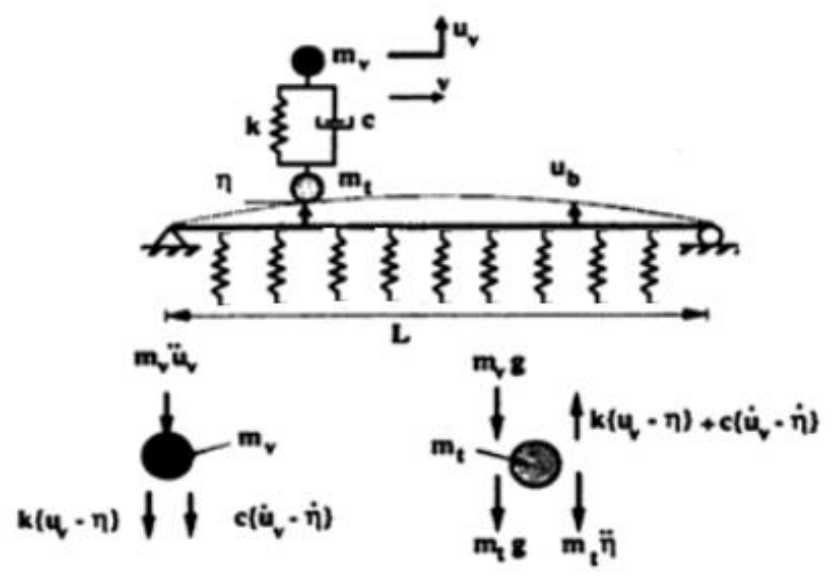

Fig. (5). Free body diagram of a floating bridge traversed by a moving vehicle. (modified from [18]).

\section{EXPERIMENTAL PROGRAM}

A model ribbon pontoon floating bridge was designed and built in the laboratory to research the global response of floating bridges under two axle dynamic loading. The results from experimental test program are used to validate the analytical model developed for ribbon floating bridges. Fig. (6) shows an overview of the model ribbon pontoon bridge and the linear variable displacement transducers (LVDT) used to measure vertical displacements along the length of the bridge.

The model bridge was made with high density polystyrene (HDPS), with a constant width of $350 \mathrm{~mm}$ and thickness of $25 \mathrm{~mm}$. Three different types of floating bridges were built: 2-pontoon bridge (each pontoon with a length of $1200 \mathrm{~mm}$ ), a 4-pontoon bridge (each pontoon with a length of $600 \mathrm{~mm}$ ) and an 8-pontoon bridge (each pontoon with a length of $300 \mathrm{~mm}$ ). The model bridge was a 1/23-scale model of a prototype with length of $55000 \mathrm{~mm}$ and a width of $8120 \mathrm{~mm}$. The overall length of the model ribbon pontoon floating bridge was $2400 \mathrm{~mm}$. The density of the HDPS was $28.4 \mathrm{~kg} / \mathrm{m}^{3}$ and the elastic modulus was $4.30 \mathrm{MPa}$. The model ribbon pontoon floating bridge had a track that ran along the center to ensure the car remained on a straight path and prevented it from going off the edges of the bridge. There were two plastic hinges between adjacent pontoons

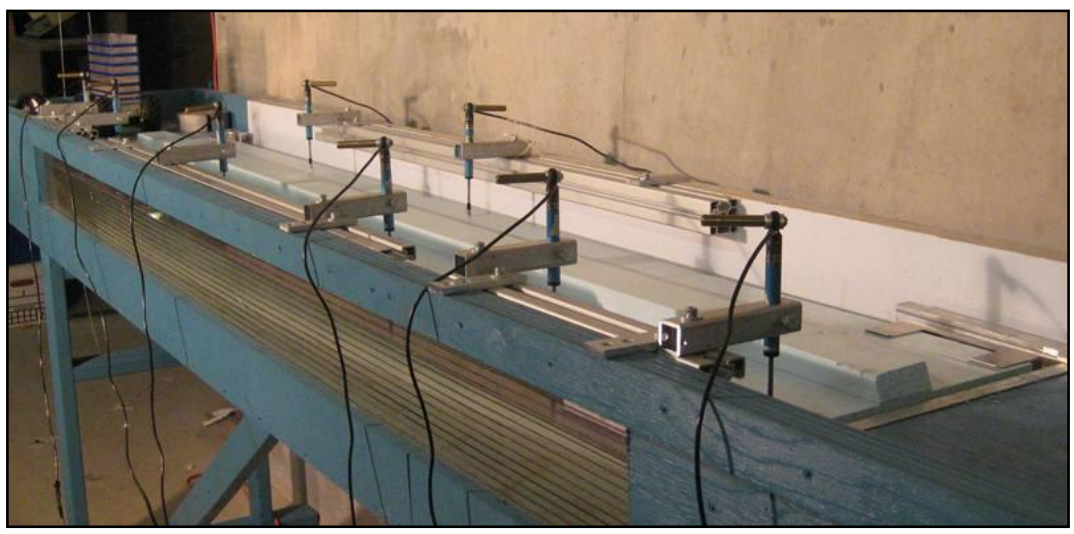

Fig. (6). Overview of model ribbon floating bridge. 
that allowed for rotation about the transverse axis of the bridge. The floating bridge was simply supported at the ends where they were attached to the bank by custom designed pinned brackets. A plywood water tank with a plexi-glass side was used to simulate the water. On either end of the tank, a platform was constructed for the car to enter and exit the bridge deck. The platforms also ensure the car travelled at a constant speed when it makes contact with the bridge.

The model vehicle was a two-axle car with an axle spacing of $200 \mathrm{~mm}$ (Fig. 7a). The cart attachment on top of the chassis guaranteed the variance of not only the speed and axle spacing, but the mass of the model vehicle as well. The mass was altered using a known weight of ballast. The usage of ballast and a symmetrically designed car, distributed the load evenly and symmetrically over the front and rear wheels. The ballast was weighed by a calibrated scale and poured into the cart. It was then tamped to ensure that it was evenly distributed over the length and depth of the cart.

The car was run by a "Tamiya High Power Gear box". This gear box was connected to an "Agilent Single Output

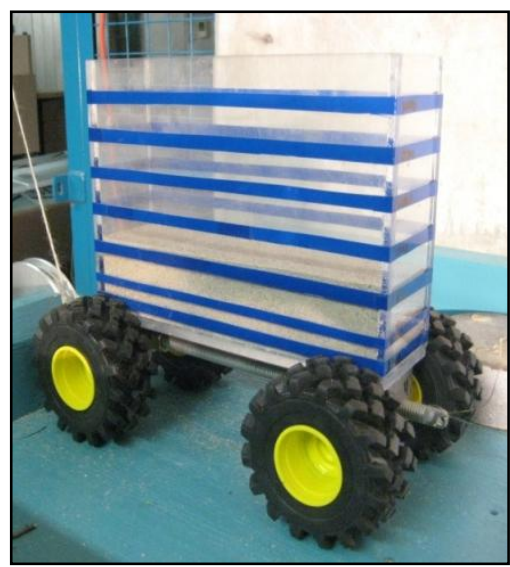

(a)
DC Power Supply" that enabled the variation of voltage to adjust the speed of the car. The gear box had a dowel attached to the drive shaft that ran a line connected to the front of the car. The line attached to the car was in constant tension for the duration of the test.

A series of LVDTs were set up at eight locations on each of the bridges (Fig. 7b). They were secured by brackets onto the tank that enabled vertical and horizontal adjustments of the LVDTs. The LVDT's were powered by a five volt Cybernen power source and were connected to a National Instruments compact data acquisition system (DAQ). Each LVDT was calibrated separately by compressing the moving core to a set distance, measured by a caliper while monitoring the change in voltage before and after the compression.

Attached to the rear end of the car was an additional tension line that was connected to a pulley. This pulley was fastened to a drive shaft of a ten-turn potentiometer. The motor was also connected to the data acquisition system. The variance in voltage transmitted through the motor, in combination with its calibration factor, allowed for the

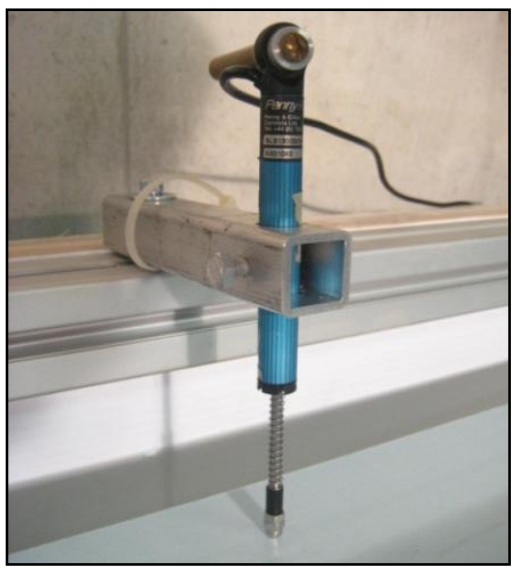

(b)

Fig. (7). (a) Model Car (b) LVDT.

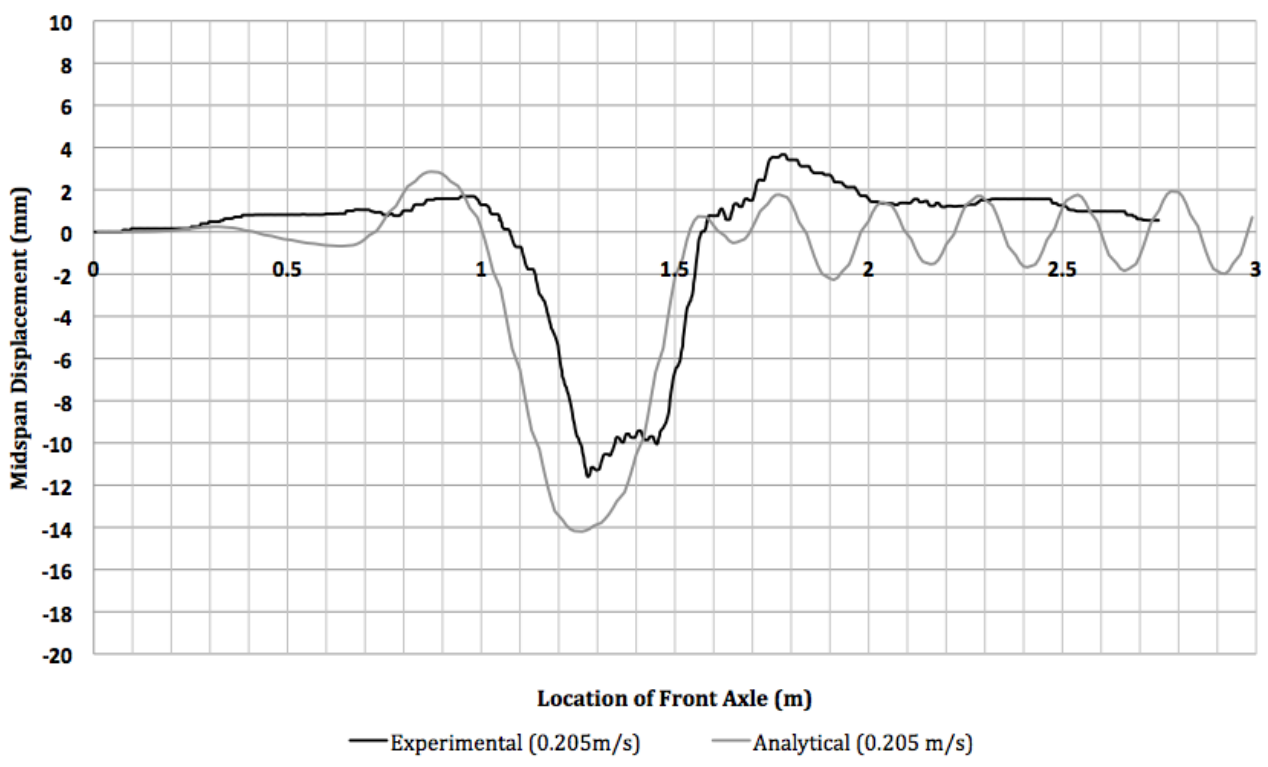

Fig. (8). Typical analytical and experimental midspan displacements for 8-pontoon ribbon floating bridge $-1.5 \mathrm{~kg}$. 
calculation of the speed of the car for each experiment. The calibration factor was the ratio of a set distance of travel of the car to the change in voltage.

All of the recorded information from the DAQ, was automatically saved in a text file, which was compared to that of the analytical model output. The analytical model required a number of inputs: mass/unit length, number of pontoons, length of pontoon, axle spacing, pontoon moment of inertia, modulus of elasticity, and vehicle velocity to complete the analysis. Prior to the experiment these values were calculated or measured and later input for the numerical analysis.

\section{PRESENTATION AND DISCUSSION}

The model ribbon pontoon floating bridges were analyzed using the developed numerical model and the results compared with the experimental results. Table $\mathbf{1}$ presents a series of experiments carried out on the model bridge for different vehicle masses and speeds. In total 24 experiments are presented for 2-pontoon, 4-pontoon, and 8pontoon ribbon floating bridges subjected to $1.5-\mathrm{kg}, 2.0-\mathrm{kg}$, and $2.5-\mathrm{kg}$ vehicle masses. The vehicle velocities used in the experiments varied $0.158 \mathrm{~m} / \mathrm{s}(13.1 \mathrm{~km} / \mathrm{hr})$ and $0.271 \mathrm{~m} / \mathrm{s}$ $(22.4 \mathrm{~km} / \mathrm{hr})$. Table 2 presents the experimental program and compared with the corresponding analytical results. The percent error between experimental and analytical results varied between 12.8 and $38.6 \%$.

In general, the vertical midspan displacements from the analytical model exceed the corresponding experimental vertical midspan displacements. Therefore, the analytical model in its current from will yield conservative designs from the standpoint of safety. As expected, an increase in the number of pontoons results in increase in vertical midspan displacement of the bridge. These results are due to the reduction in stiffness or increased flexibility of the bridge

Table 1. Model and prototype vehicle mass and speed.

\begin{tabular}{|c|c|c|c|c|c|}
\hline Trial & Number of Pontoons & $\begin{array}{c}\text { Model Vehicle Mass } \\
\text { (kg) }\end{array}$ & $\begin{array}{c}\text { Prototype Vehicle Mass } \\
\text { (kg) }\end{array}$ & $\begin{array}{c}\text { Model Vehicle Speed } \\
(\mathrm{m} / \mathrm{s})\end{array}$ & $\begin{array}{c}\text { Prototype Vehicle Speed } \\
(\mathbf{k m} / \mathbf{h r})\end{array}$ \\
\hline 1 & 8 & 1.5 & 18250 & 0.174 & 14.4 \\
\hline 2 & 8 & 1.5 & 18250 & 0.205 & 17.0 \\
\hline 3 & 8 & 1.5 & 18250 & 0.240 & 19.9 \\
\hline 5 & 8 & 2.0 & 24300 & 0.185 & 15.3 \\
\hline 6 & 8 & 2.0 & 24300 & 0.242 & 20.0 \\
\hline 7 & 4 & 1.5 & 18250 & 0.164 & 13.6 \\
\hline 8 & 4 & 1.5 & 18250 & 0.213 & 17.6 \\
\hline 11 & 4 & 2.0 & 24300 & 0.177 & 14.7 \\
\hline 12 & 4 & 2.0 & 24300 & 0.261 & 21.6 \\
\hline 13 & 4 & 2.5 & 30400 & 0.158 & 13.1 \\
\hline 14 & 4 & 2.5 & 30400 & 0.216 & 17.9 \\
\hline 15 & 4 & 2.5 & 30400 & 0.256 & 21.2 \\
\hline 16 & 2 & 1.5 & 18250 & 0.160 & 13.2 \\
\hline 17 & 2 & 1.5 & 18250 & 0.210 & 17.4 \\
\hline 18 & 2 & 1.5 & 18250 & 0.256 & 21.2 \\
\hline 23 & 2 & 2.5 & 30400 & 0.205 & 17.0 \\
\hline 24 & 2 & 2.5 & 30400 & 0.265 & 21.9 \\
\hline
\end{tabular}


with increased number of pontoons or hinge supports. Thus, the 8-pontoon ribbon floating bridge exhibits the largest vertical midspan displacement while the 2-pontoon ribbon floating bridge exhibits the least vertical midspan displacement. This trend was constant in both analytical and experimental results. For example, for the $1.5-\mathrm{kg}$ vehicle, the 8 pontoon, 4-pontoon, and 2-pontoon ribbon floating bridge had analytical vertical midspan displacements of $-14.7 \mathrm{~mm}$, $10.6 \mathrm{~mm}$, and $-10.4 \mathrm{~mm}$ respectively and experimental vertical midspan displacements in the range of $-7.63 \mathrm{~mm}$, $6.42 \mathrm{~mm}$, and $-5.09 \mathrm{~mm}$ respectively. Slight variations in the vehicle speeds exist between the different experiments as the voltage supplied to the motor of vehicle usually results in slightly different vehicle speed. The effect of increased vehicle mass is increased midspan displacement of the bridge, regardless of the number of pontoons in the floating bridge (Table 2).
Fig. (8) and Fig. (9) presents the typical comparison between the analytical and experimental vertical midspan displace-ment of the 8-pontton floating bridge for $1.5-\mathrm{kg}$ and $2.0-\mathrm{kg}$ vehicle respectively. In general, good correlation is observed between the experimental and analytical midspan displacement as the vehicle travels across the bridge. The maximum midspan displacement occurs when the vehicle is at midspan of the bridge. Typically, in the experimental tests the midspan displacement is upwards as the vehicle enters the bridge up to about $1.0-\mathrm{m}$ point where the midspan displacement is downwards. At about the $1.5-\mathrm{m}$ point across the bridge, the midspan displacement is again upwards until the vehicle exits the bridge. Conversely, the analytical model predicts downwards midspan displacement as the vehicle enters the bridge up to about the $0.7-\mathrm{m}$ point where the midspan displacement are upwards and then downwards at about the $1.0-\mathrm{m}$ point as was for the experimental. Between

Table 2. Comparison of experimental and analytical results.

\begin{tabular}{|c|c|c|c|c|c|c|}
\hline Trial & Number of Pontoons & Vehicle Mass (kg) & Speed $(\mathbf{m} / \mathbf{s})$ & \multicolumn{2}{|c|}{ Maximum Midspan Displacement (mm) } & Error $(\%)$ \\
\hline 2 & 8 & 1.5 & 0.205 & -13.8 & -11.3 & 22.1 \\
\hline 3 & 8 & 1.5 & 0.240 & -14.7 & -10.6 & 38.6 \\
\hline 5 & 8 & 2.0 & 0.185 & -18.7 & -15.4 & 17.6 \\
\hline 6 & 8 & 2.0 & 0.242 & -19.6 & -14.8 & 32.4 \\
\hline 7 & 4 & 1.5 & 0.164 & -9.63 & -7.87 & 22.3 \\
\hline 8 & 4 & 1.5 & 0.213 & -9.98 & -7.63 & 30.7 \\
\hline 11 & 4 & 2.0 & 0.177 & -13.2 & -11.1 & 18.9 \\
\hline 12 & 4 & 2.0 & 0.261 & -13.7 & -10.9 & 25.6 \\
\hline 13 & 4 & 2.5 & 0.158 & -16.6 & -14.1 & 17.7 \\
\hline 14 & 4 & 2.5 & 0.216 & -16.9 & -13.4 & 26.1 \\
\hline 15 & 4 & 2.5 & 0.256 & -15.9 & -14.1 & 12.8 \\
\hline 16 & 2 & 1.5 & 0.160 & -6.24 & -5.09 & 22.6 \\
\hline 17 & 2 & 1.5 & 0.210 & -6.42 & -5.58 & 15.1 \\
\hline 23 & 2 & 2.5 & 0.205 & -10.7 & -9.16 & 17.2 \\
\hline 24 & 2 & 2.5 & 0.265 & -10.7 & -8.58 & 25.2 \\
\hline
\end{tabular}




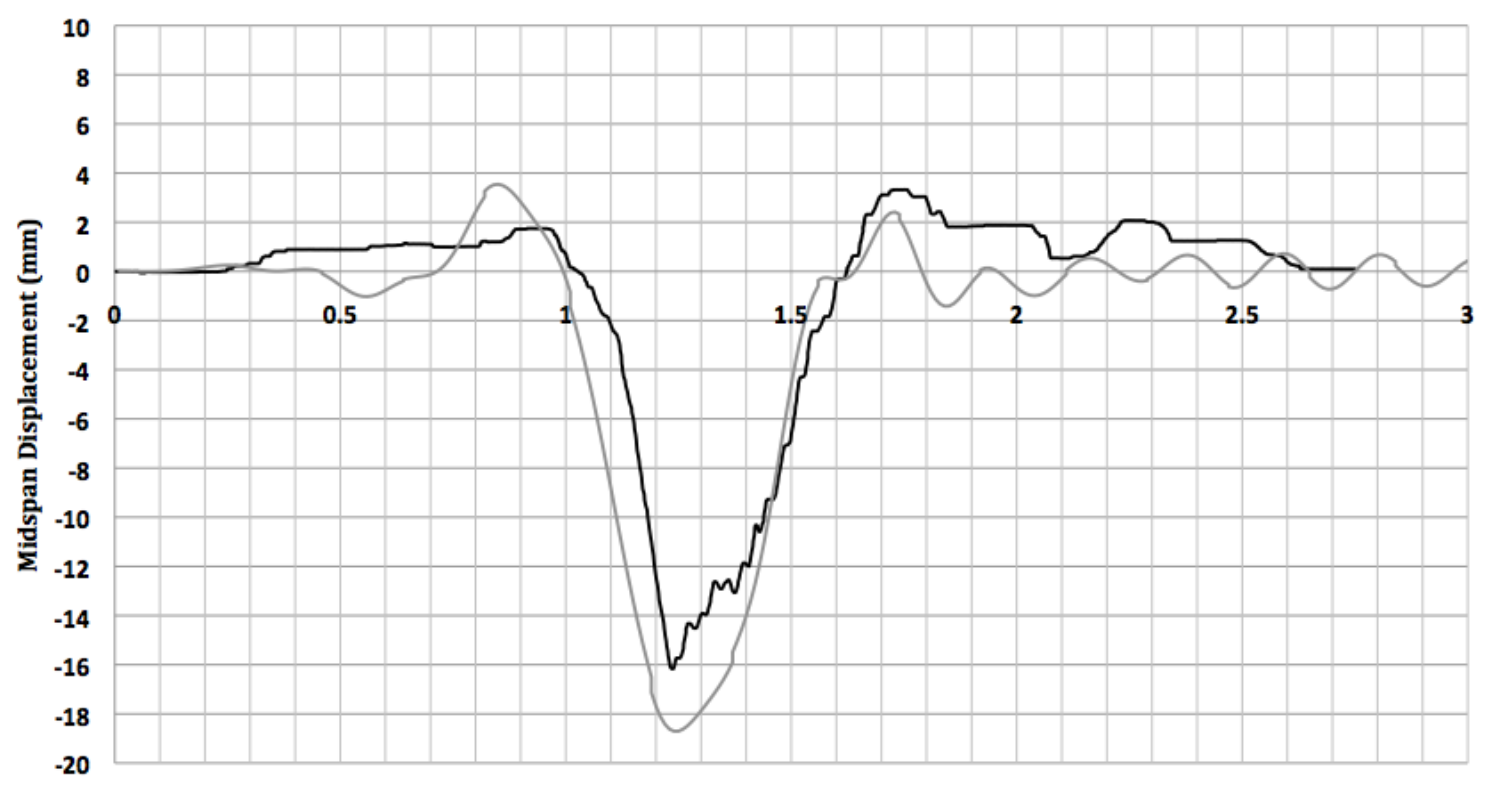

Location of Front Axle (m)

—Experimental $(0.158 \mathrm{~m} / \mathrm{s}) \quad$ - Analytical $(0.158 \mathrm{~m} / \mathrm{s})$

Fig. (9). Typical analytical and experimental midspan displacements for 8-pontoon ribbon floating bridge $-2.0 \mathrm{~kg}$.

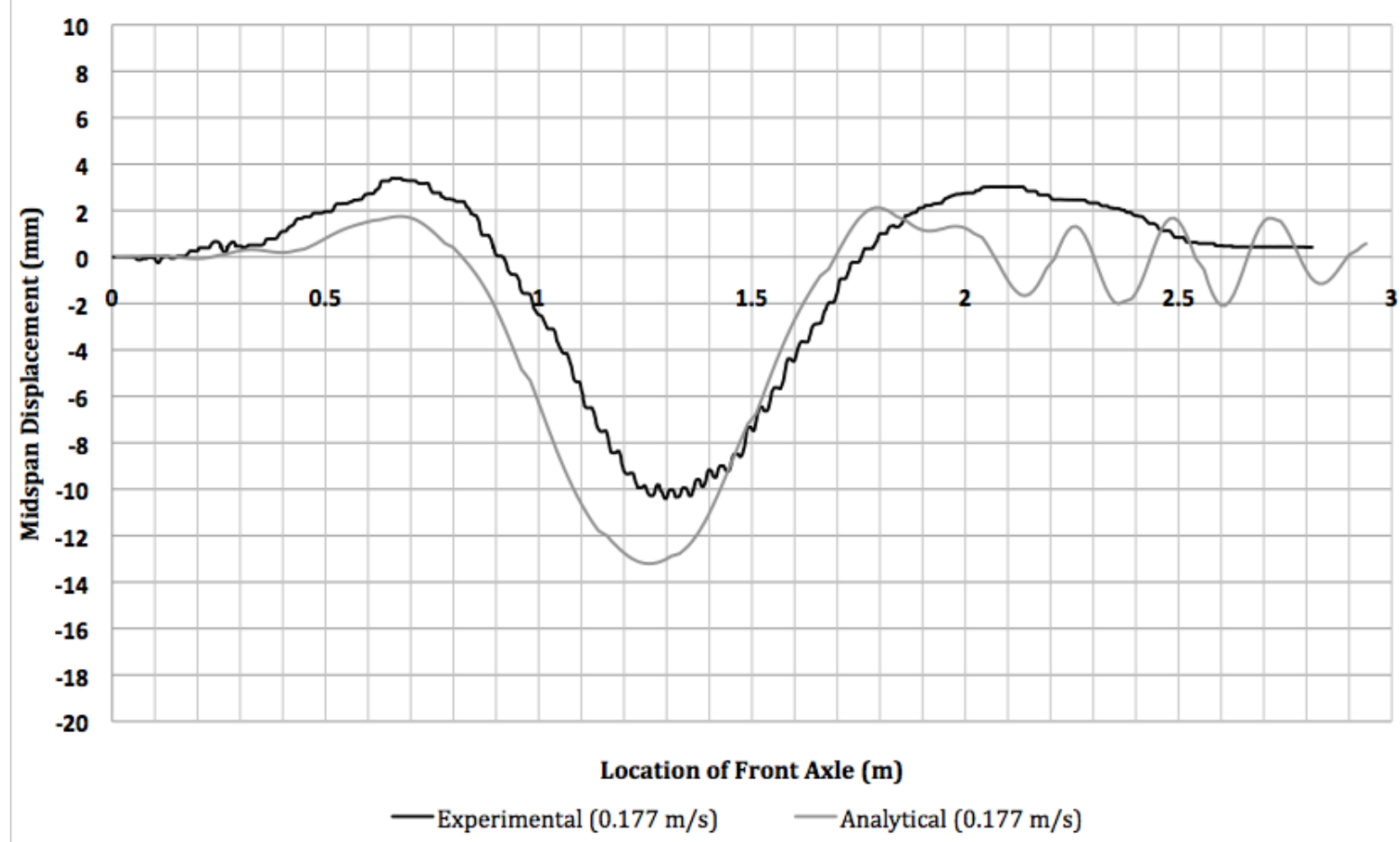

Fig. (10). Typical analytical and experimental midspan displacements for 4-pontoon ribbon floating bridge - $1.5 \mathrm{~kg}$.

the $1.0-\mathrm{m}$ and $1.5-\mathrm{m}$ point the midspan displace-ment of the bridge is downwards as was for the experimental results. The slight difference in behaviour is probably attributable to the friction in the hinges, which was not considered in the analytical. Subsequent development of the analytical model will investigate this difference in behaviour.
Fig. (10) and Fig. (11) present the typical comparison of the analytical and experimental midspan displacement of the 4-pontoon floating bridge for $1.5-\mathrm{kg}$ and $2.0-\mathrm{kg}$ vehicle respectively. The $1.5-\mathrm{kg}$ vehicle was for a speed of 0.177 $\mathrm{m} / \mathrm{s}$ while the $2.0-\mathrm{kg}$ vehicle was travelling at a speed of $0.261 \mathrm{~m} / \mathrm{s}$. Very good and consistent correlation is observed between the experimental and analytical vertical midspan 
displacement of the 4-pontoon floating bridge due to the passage of the vehicles. Fig. (10) and Fig. (11) show that as the vehicles enter the floating bridge, up to about the $0.8-\mathrm{m}$ point on the bridge, the midspan displacement is upward and that the analytical model under predicts the experimental displacement. However, between the $0.8-\mathrm{m}$ and $1.7-\mathrm{m}$ point the midspan vertical displacement is downwards and the analytical model over predicts the experimental midspan displacement.

Fig. (12), Fig. (13), and Fig. (14) present the analytical and experimental displacements of the 2-pontoon ribbon floating bridge under the $1.5-\mathrm{kg}, 2.0-\mathrm{kg}$, and $2.5-\mathrm{kg}$ vehicle

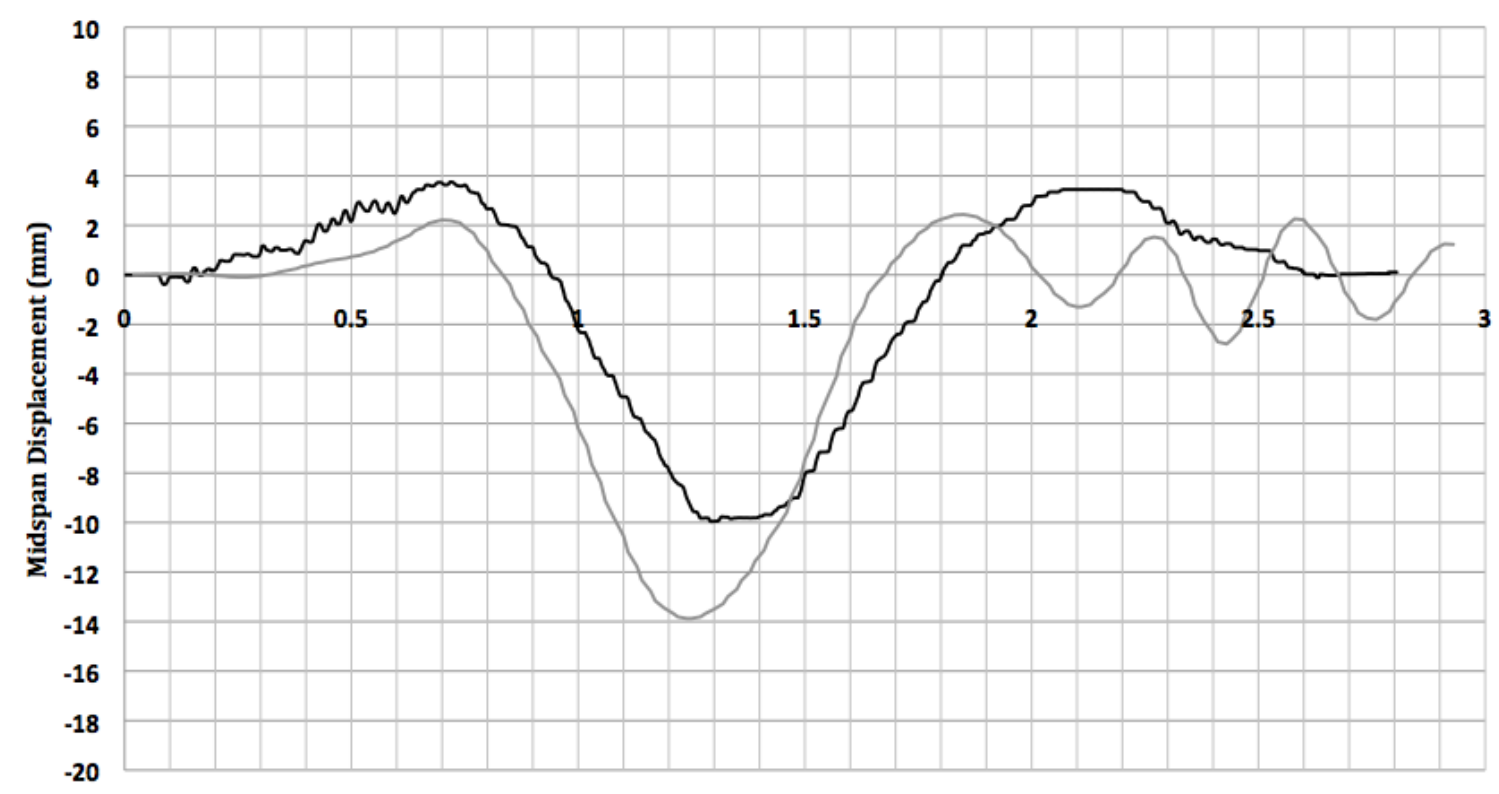

Location of Front Axle (m)

—Experimental $(0.261 \mathrm{~m} / \mathrm{s}) \quad$ - Analytical $(0.261 \mathrm{~m} / \mathrm{s})$

Fig. (11). Typical analytical and experimental midspan displacements for 4-pontoon ribbon floating bridge $-2.0 \mathrm{~kg}$.

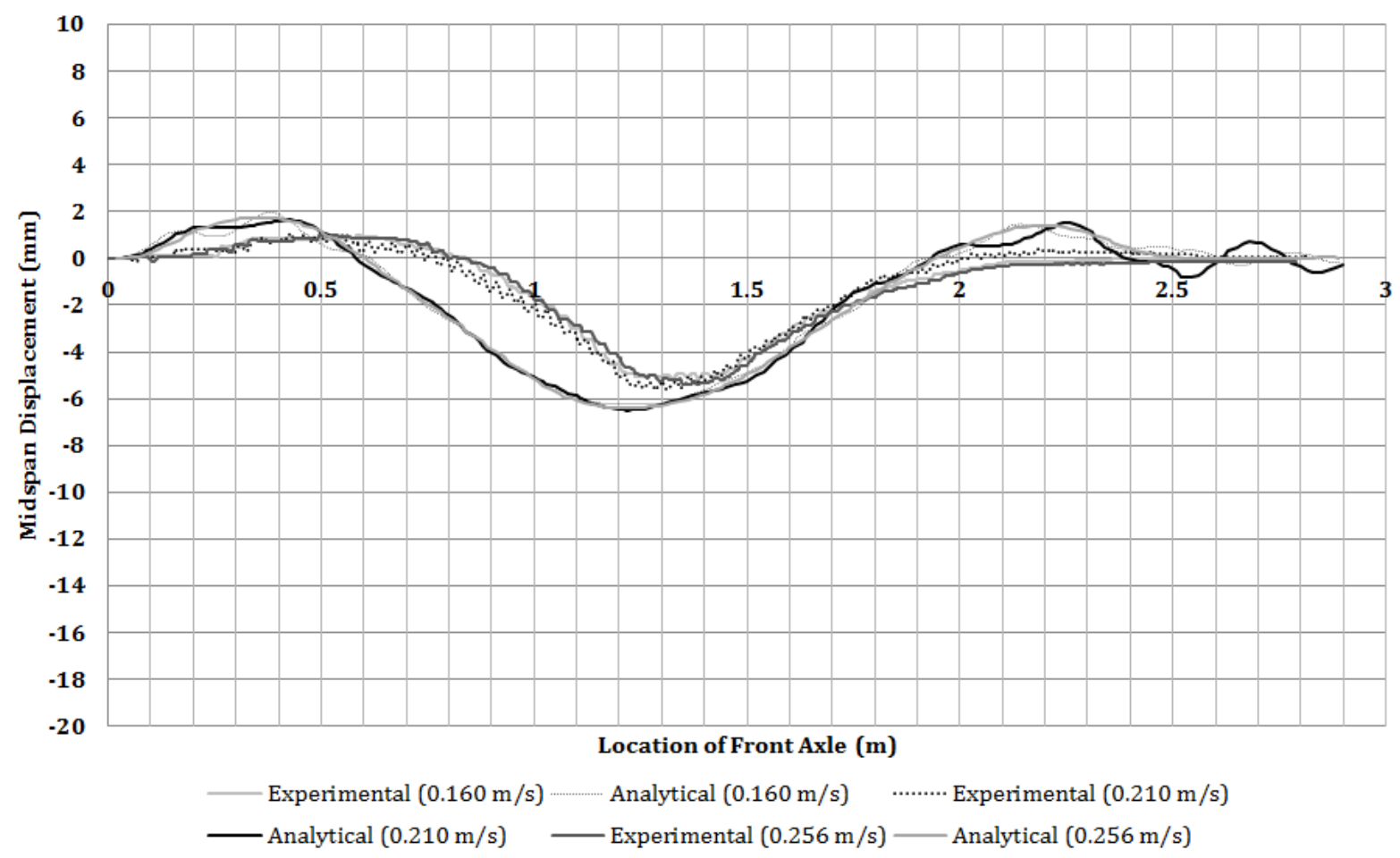

Fig. (12). Effect of speed on midspan displacements for 2-pontoon ribbon floating bridge $-1.5 \mathrm{~kg}$. 


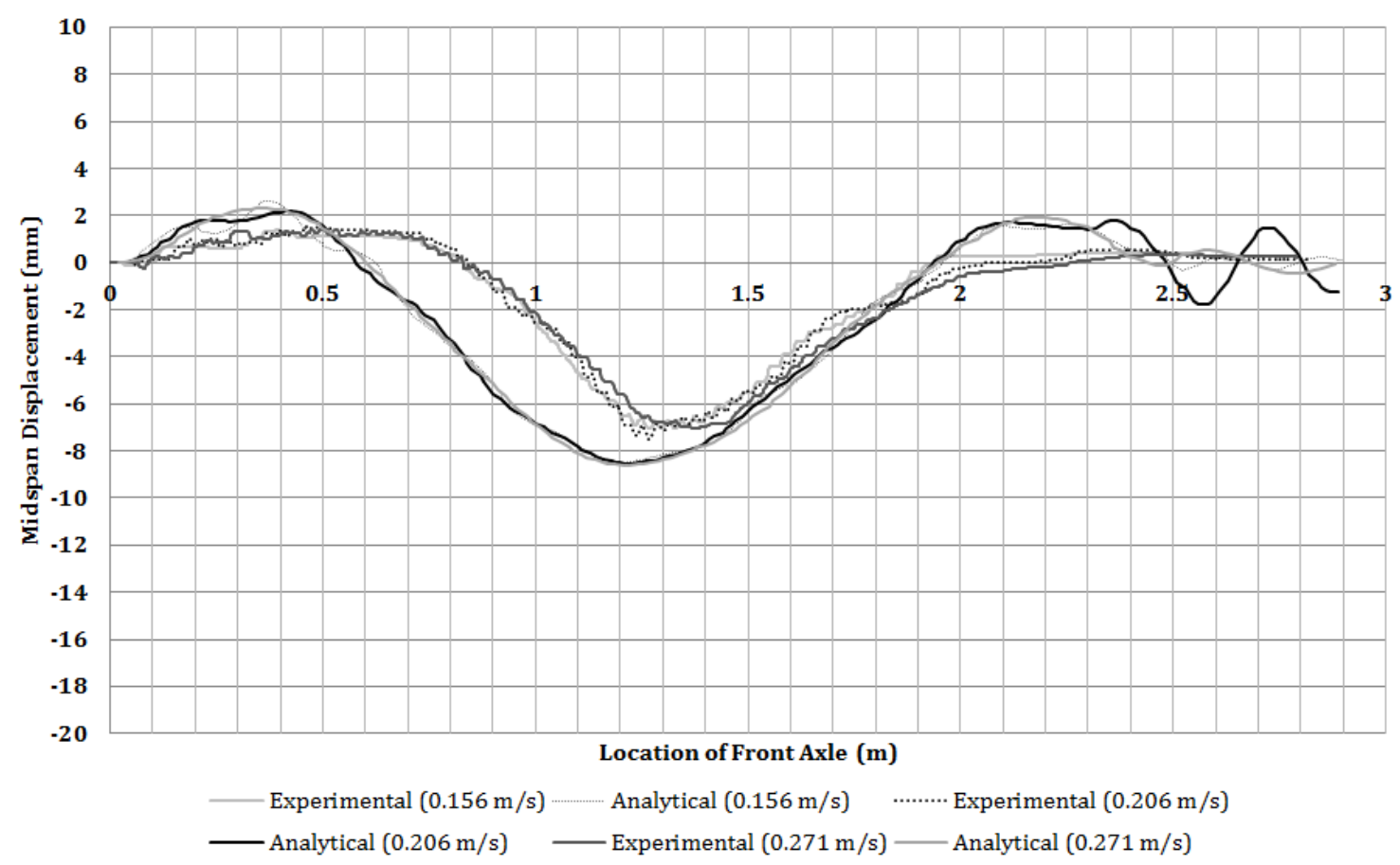

Fig. (13). Effect of speed on midspan displacements for 2-pontoon ribbon floating bridge $-2.0 \mathrm{~kg}$.

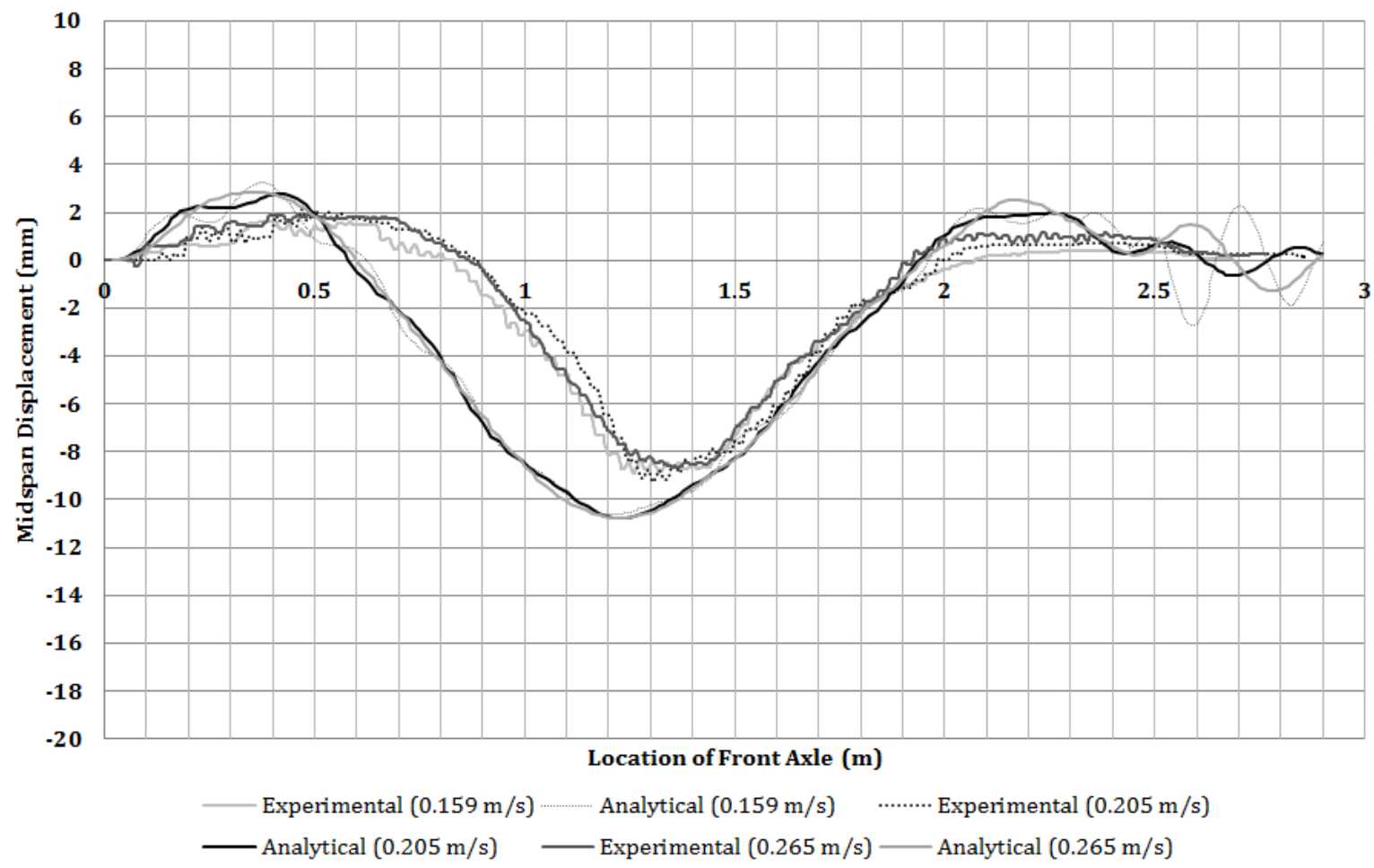

Fig. (14). Effect of speed on midspan displacements for 2-pontoon ribbon floating bridge $-2.5 \mathrm{~kg}$.

loading. The figures show the effect of vehicle speed on midspan displacement of the 2-pontoon bridge. As for the 8pontoon and 4-pontoon bridge, it is evident that the effect of vehicle speed on the midspan displacement of ribbon pontoon floating bridges is inconclusive. In general, the analytical results show a slight increase in midspan displacement with increase in vehicle speed while no consistent trend is obvious from the experimental results (Table 1 and Fig. (12), Fig. (13), and Fig. (14)).

Typical deflected shapes of the 8-pontoon, 4-pontoon, and 2-pontoon floating bridges for a vehicle located at midspan of the bridge are presented in Fig. (15), Fig. (16), and Fig. (17) respectively. As well, the maximum displacements of the bridges are also presented. Good correlation is noted for the 4-pontoon and 2-pontoon bridges with a 


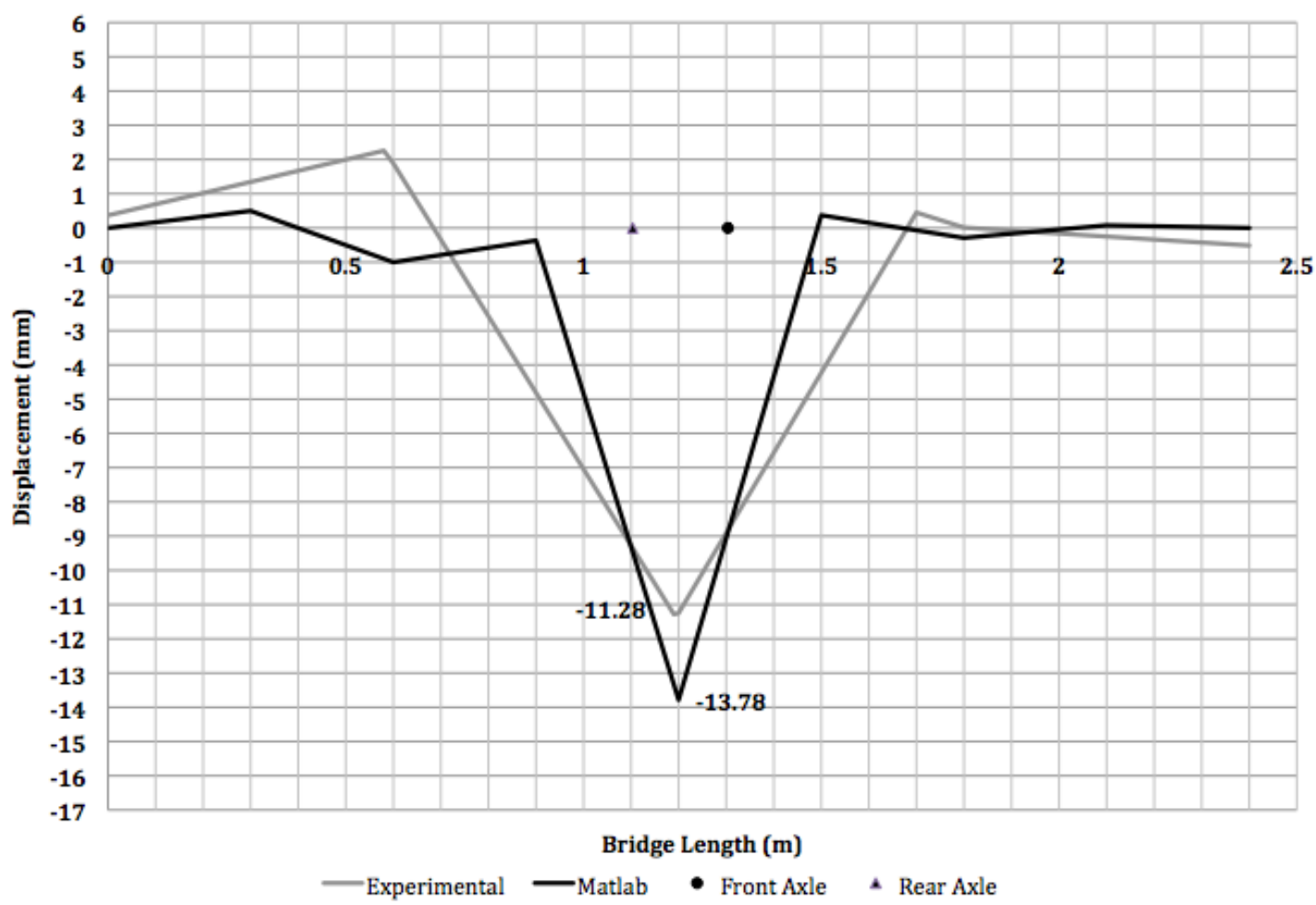

Fig. (15). Typical deflected shape of 8-pontoon bridge.

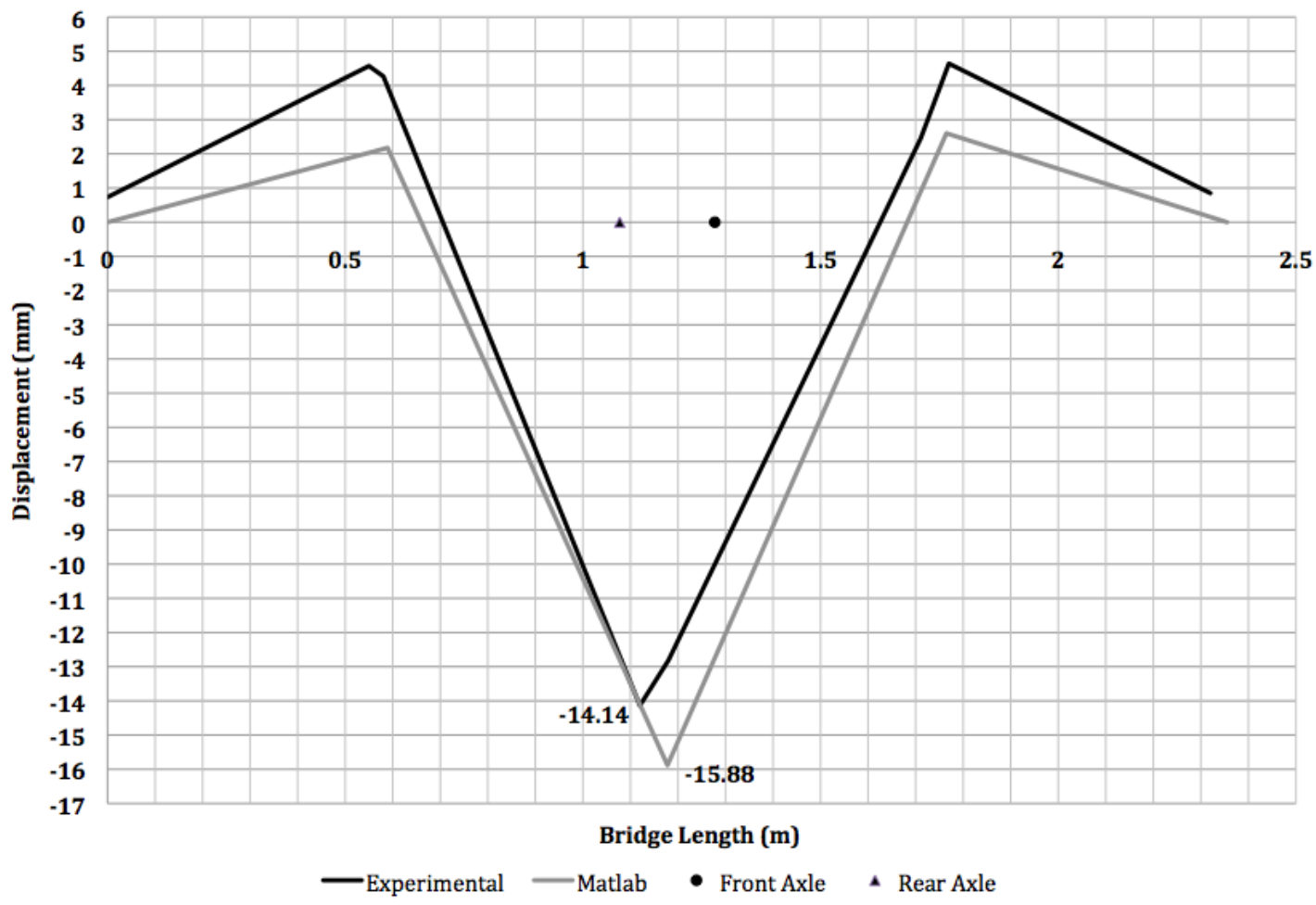

Fig. (16). Typical deflected shape of 4-pontoon bridge.

slight over prediction of the maximum midspan displacement by the analytical model. The correlation for the 8pontoon bridge is not as good since the analytical model fails to accurately predict the quarter-point displacements when the vehicle is at midspan. The reason for this behaviour is that the experimental displacements were measured at only the quarter-points along the bridge length, and thus the displacement at the intermediate $\left(1 / 8^{\text {th }}\right.$ point) hinges are assumed to be the average of the measured displacement of the two adjacent hinges. Whereas, the analytical model calculates the displacement for all hinge (including at the $1 / 8^{\text {th }}$ point) locations. 


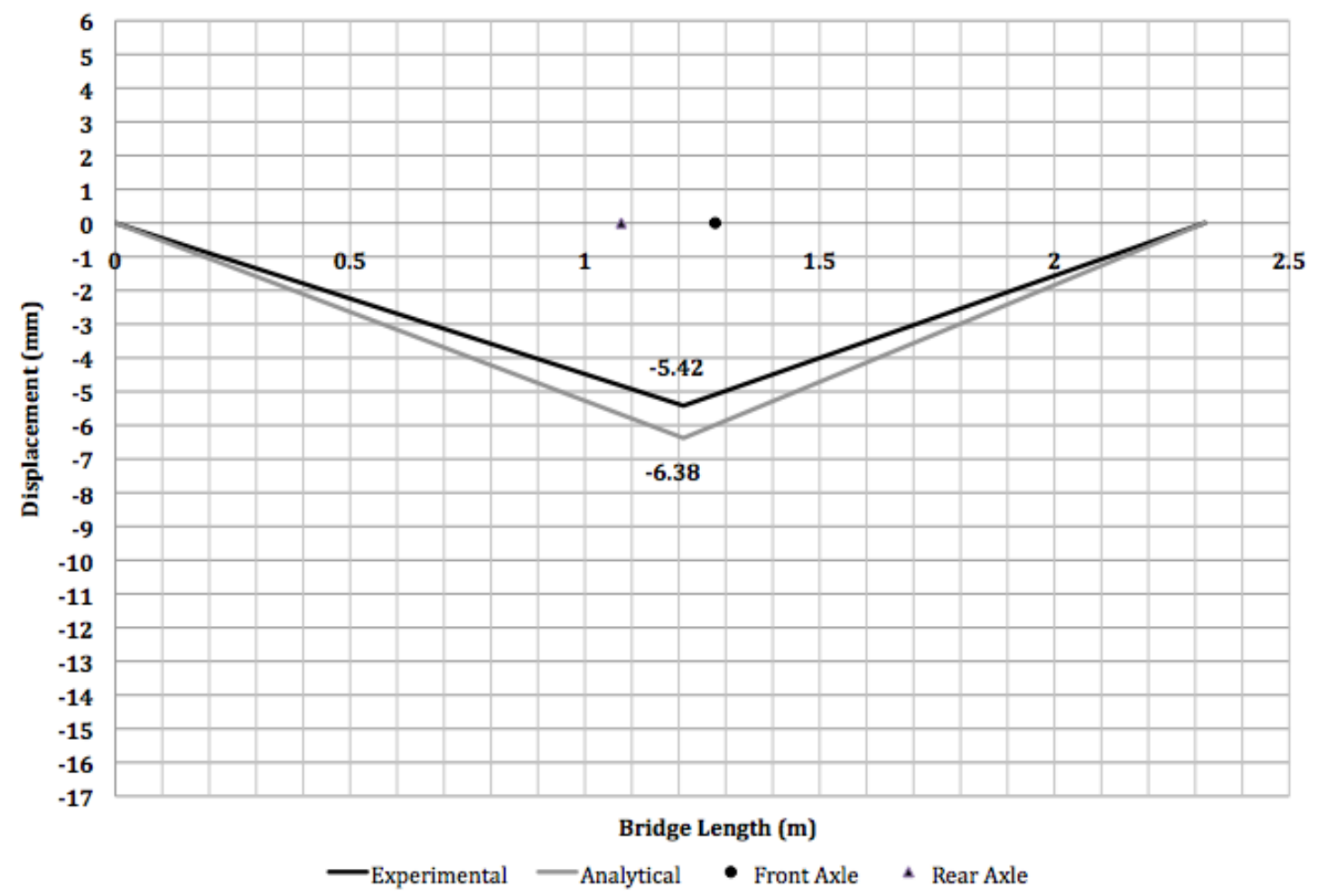

Fig. (17). Typical deflected shape of 2-pontoon bridge.

\section{CONCLUSIONS}

This paper presented the details and results of analytical and experimental research program designed to investigate the behavior of ribbon floating bridges under a moving twoaxle vehicle loading. One of the main objectives of the research was to examine the potential of optimizing the transportability of supplies across these types of bridge. As expected, pontoons bridges with more pontoons of smaller lengths experience larger deflections than bridges composed of longer and lesser number of pontoons. For all three bridges tested, comprised of 2-pontoon, 4-pontoon and 8pontoons, the analytically estimated midspan displacements compared reasonably well with those measured on the experimental models. No significant change in ribbon floating bridge midspan displacement was observed under different vehicle speeds. Good correlation was achieved between the analytical and experimental results, the percent error for midspan displacement of all trials ranged from 12$38 \%$. The results showed that increasing the traffic traversing the pontoon bridges can be achieved through the use of larger pontoon units, and increasing the speed of the vehicles.

This research program is a preliminary study for an ongoing project. The study of effect of vehicle-bridge dynamics on maximum response is continuing. In addition the distance between two successive vehicles is currently being investigated. Furthermore, the next phase of the study is more comprehensive including precise scales, dimensions, weights, speeds and a more accurate hinging system between successive pontoons. This research study is expected to provide more realistic and accurate results to determine the effects of weight-speed combination on the optimum transportability across these bridges.

\section{ABBREVIATIONS}

$B$

$\left[C_{G}\right] \quad=\quad$ Global damping matrix of bridge

DAQ $=$ Data acquisition system

$\{D\} \quad=\quad$ Global displacement vector of bridge

$\{\dot{D}\}$

$\{\ddot{D}\}$

$=$

Global velocity vector of bridge

$=$ Global acceleration vector of bridge

$E \quad=\quad$ Elastic modulus

$g$

HDPS

Gravitational acceleration

$=$

$=\quad$ High density polystyrene

I

$k_{w}$

$\left[K_{G}\right]$

$\mathrm{L}$

LVDT

$=\quad$ Moment of inertia

$=$

Buoyancy stiffness

$=\quad$ Global stiffness matrix of bridge

$=\quad$ Bridge span

$=$

Linear variable displacement transducers

MLC

$=\quad$ Military Load Classification

$\left[M_{G}\right]$

$[P]$

Global mass matrix of bridge

$=$

Global load vector acting on bridge

$u(x, t) \quad=\quad$ Deflection-time function of bridge

$\alpha$

$=$ Stiffness proportional damping constant 


$\begin{array}{lll}\beta & = & \begin{array}{l}\text { Mass proportional damping } \\ \text { constant }\end{array} \\ \Delta_{1 y}, \Delta_{2 y} & = & \begin{array}{l}\text { Nodal vertical displacements } \\ \text { along } y \text {-axis }\end{array} \\ \eta & = & \begin{array}{l}\text { Equation of motion of vehicle } \\ \text { point of contact with bridge }\end{array} \\ \theta_{1 z}, \theta_{2 z} & = & \begin{array}{l}\text { Nodal rotations about } z \text {-axis } \\ \text { Density of water }\end{array} \\ \rho_{w} & = & \begin{array}{l}\text { Shape functions for bending } \\ \text { behaviour } \\ \psi_{1}, \psi_{2}, \psi_{3}, \psi_{4}\end{array} \\ \psi_{t 1}, \psi_{t 2} & =\begin{array}{l}\text { Shape functions for torsional and } \\ \text { axial behaviour. }\end{array}\end{array}$

\section{CONFLICT OF INTEREST}

The authors confirm that this article content has no conflicts of interest.

\section{ACKNOWLEDGEMENTS}

None declared.

\section{REFERENCES}

[1] E. Watanabe, T. Utsunomiya, "Analysis and design of floating bridges", Steel Construct., Prog. Struct. Eng. Mat., vol. 5, no. 3, pp. 127-144, 2003.

[2] D. J. Brown, Bridges: three thousand 3years of defying nature, Richmond Hill, Ont.: Firefly Books, 2005.

[3] M. S. Seif, Y. Inoue, "Dynamic analysis of floating bridges", Marine Struct., vol. 11, pp. 29-46, 1998 .

[4] M. S. Seif, R. T. P. Koulaei, "Floating bridge modeling and analysis", Sci. Iranica., vol. 12, no. 2, pp. 199-206, 2005.

[5] E. Watanabe, C. M. Wang, T. Utsunomiya, T. Moan, "Very large floating structures: applications, analysis and design", Centre for Offshore Research and Engineering, National University of Singapore, CORE Report no. 2004-02. 2004

[6] W. F. Chen, L. Duan, "Bridge Engineering Handbook", CRC Press LLC, Boca Raton, Florida, USA, 1999

[7] S. Oka, N. Kumamoto, K. Inoue, K. Ikegami, H. Seto, S. Ueda, T. Maruyama, "Elastic response analysis method for floating bridges in waves", Mitsubishi Heavy Industries, Ltd. Technical Review, vol. 37, no. 2, pp. 40-44, 2000.

[8] CNIM - Military Bridges, Floating Bridges and Rafts, and Assault Bridges - Army Technology." N.p., n.d. Web. 26 Sept. 2012.< http://www.armytechnology.com/contractors/enginee-ring/cnim1/>

[9] $\quad$ Floating Bridge (Pontoon Bridge) PMP-60." VIKST. N.p., n.d. Web. 26 Sept. 2012. 〈http://vikst.com/ponton_pmp_en.htm〉

[10] D. Rosenthal , R. Connor, J. C. Peterson ,"Trilateral Design and Test Code for Military Bridging and Gap-Crossing Equipment", USA, 2005

[11] http://www.army.gr/default.php?pname=Article\&art_id=56413\&ca $\mathrm{t} \_$id $=14 \& l a=2$ [accessed:] February 21, 2013]

[12] O. M. I. El-Desouky, 2011, "Dynamic Behaviour of Short-Term Floating Bridges", PhD. Thesis, Carleton University, Ottawa, Canada.

[13] C. Georgiadis, "Finite element modeling of the response of long floating structures under harmonic excitation", Proceedings of the Third International Offshore Mechanics and Arctic Engineering Symposium, American Society of Mechanical Engineering ASME, vol. 1 , pp. 246-252, 1984.

[14] J. S. Wu, J. J. Sheu , "An exact solution for a simplified model of the heave and pitch motions of a ship hull due to a moving load and a comparison with some experimental results", J. Sound Vib., vol. 192, no. 2, pp. 495-520, 1996.

[15] J. S. Wu, P. Y. Shih, "Moving-load-induced vibrations of a moored floating bridge", Comp. Struct., vol. 66, no. 4, pp. 435-461, 1998.

[16] D. Thambiratnam, Y. Zhuge, "Dynamic analysis of beams on an elastic foundation subjected to moving loads", J. Sound Vib., Vol. 198, no. 2, pp. 149-169, 1996.

[17] J. Zhang, G. P. Miao, J. X. Liu, W. J. Sun, "Analytical models of floating bridges subjected by moving loads for different water depths", J. Hydrodynam., vol. 20, no. 5, pp. 537-546, 2008.

[18] J. L. Humar, A. Kashif, "Dynamic response of bridges under travelling loads", Can. J. Civil Eng., vol. 20, pp. 287-298, 1993.

[19] L. C. Qiu, "Modeling and Simulation of transient responses of a flexible beam floating in finite depth water under moving loads", Appl. Math. Model, vol. 33, no. 3, pp. 1620-1632, 2009.

[20] S. S. Rao, "The Finite Element Method in Engineering", Fourth Edition, Elsevier Science \& Technology Books, 2004.

[21] ISSC (2006d), Report of Specialist Task Committee VI.2, "Very Large Floating Structures", In P. Frieze and R. Shenoi (Eds.), Proceedings of the 16th International Ship and Offshore Structures Congress, Elsevier, Southampton, UK, pp. 391-442, 2006.

[22] J. L. Humar, “ Dynamics of structures", $2^{\text {nd }}$ ed. CRC Press: USA, 2012

[23] B. Hornbeck, K. Johannes and C. Richard, " Trilateral design and test code for military bridging and gap crossing equipment" Tacom Research Development and Engineering Centre, Warren, MI, 2005.

\footnotetext{
Received: December 14, 2013 Revised: January 06, 2014 Accepted: January 06, 2014

(C) Viecili et al.; Licensee Bentham Open.

This is an open access article licensed under the terms of the Creative Commons Attribution Non-Commercial License (http://creativecommons.org/licenses/ by-nc/3.0/) which permits unrestricted, non-commercial use, distribution and reproduction in any medium, provided the work is properly cited.
} 